\title{
Nanostructured lipid carriers for incorporation of copper(II) complexes to be used against Mycobacterium tuberculosis
}

This article was published in the following Dove Press journal:

Drug Design, Development and Therapy

20 March 2017

Number of times this article has been viewed

\author{
Mariana R Sato' \\ João A Oshiro Junior' \\ Rachel TA Machado' \\ Paula C de Souza ${ }^{2}$ \\ Débora L Campos ${ }^{2}$ \\ Fernando R Pavan ${ }^{2}$ \\ Patricia B da Silva ${ }^{1, *}$ \\ Marlus Chorilli',* \\ 'Department of Drugs and Medicines, \\ Faculdade de Ciências Farmacêuticas, \\ UNESP - Univ Estadual Paulista, \\ Campus Araraquara, Araraquara, SP, \\ Brazil; '2Department of Biological \\ Sciences, Faculdade de Ciências \\ Farmacêuticas, UNESP - Univ \\ Estadual Paulista, Campus Araraquara, \\ Araraquara, SP, Brazil \\ *These authors contributed equally \\ to this work
}

Abstract: Tuberculosis (TB) is a disease caused by Mycobacterium tuberculosis. Cessation of treatment before the recommended conclusion may lead to the emergence of multidrugresistant strains. The aim of this study was to develop nanostructured lipid carriers (NLCs) for use in the treatment of M. tuberculosis. The NLCs comprised the following lipid phase: $2.07 \%$ polyoxyethylene 40 stearate, $2.05 \%$ caprylic/capric triglyceride, and $0.88 \%$ polyoxyl 40 hydrogenated castor oil; the following aqueous phase: $3.50 \%$ poloxamer 407 (F1-F6), and $0.50 \%$ cetyltrimethylammonium bromide (F7-F12); and incorporated the copper(II) complexes $\left[\mathrm{CuCl}_{2}(\mathrm{INH})_{2}\right] \cdot \mathrm{H}_{2} \mathrm{O}(1),\left[\mathrm{Cu}(\mathrm{NCS})_{2}(\mathrm{INH})_{2}\right] \cdot 5 \mathrm{H}_{2} \mathrm{O}(2)$, and $\left[\mathrm{Cu}(\mathrm{NCO})_{2}(\mathrm{INH})_{2}\right] \cdot 4 \mathrm{H}_{2} \mathrm{O}$ (3) to form compounds F11.1, F11.2, and F11.3, respectively. The mean diameter of F11, F11.1, F11.2, and F11.3 ranged from $111.27 \pm 21.86$ to $134.25 \pm 22.72 \mathrm{~nm}, 90.27 \pm 12.97$ to $116.46 \pm 9.17 \mathrm{~nm}$, $112.4 \pm 10.22$ to $149.3 \pm 15.82 \mathrm{~nm}$, and $78.65 \pm 6.00$ to $122.00 \pm 8.70 \mathrm{~nm}$, respectively. The polydispersity index values for the NLCs ranged from $0.13 \pm 0.01$ to $0.30 \pm 0.09$. The NLCs showed significant changes in zeta potential, except for F11.2, with F11, F11.1, F11.2, and F11.3 ranging from $18.87 \pm 4.04$ to $23.25 \pm 1.13 \mathrm{mV}, 17.03 \pm 1.77$ to $21.42 \pm 1.87 \mathrm{mV}, 20.51 \pm 1.88$ to $22.60 \pm 3.44 \mathrm{mV}$, and $17.80 \pm 1.96$ to $25.25 \pm 7.78 \mathrm{mV}$, respectively. Atomic force microscopy confirmed the formation of nanoscale spherical particle dispersions by the NLCs. Differential scanning calorimetry determined the melting points of the constituents of the NLCs. The in vitro activity of copper(II) complex-loaded NLCs against M. tuberculosis $\mathrm{H}_{37} \mathrm{R}_{\mathrm{v}}$ showed an improvement in the anti-TB activity of 55.4, 27.1, and 41.1 times the activity for complexes 1, 2, and 3, respectively. An in vivo acute toxicity study of complex-loaded NLCs demonstrated their reduced toxicity. The results suggest that NLCs may be a powerful tool to optimize the activity of copper(II) complexes against $M$. tuberculosis.

Keywords: tuberculosis, M. tuberculosis, nanostructured lipid carriers, copper(II) complex, in vitro activity, in vivo acute toxicity assay

\section{Introduction}

Tuberculosis (TB) is a contagious, infectious, chronic disease caused mainly by Mycobacterium tuberculosis (M. tuberculosis), which is also known as Koch's bacillus. Transmission occurs from person to person through air droplets, where the droplets containing the bacillus preferentially infect highly oxygenated organs such as the lungs. ${ }^{1}$

According to the World Health Organization (WHO), TB is the leading cause of death worldwide, followed by the human immunodeficiency virus (HIV). HIV contributes to higher mortality among co-infected patients. In 2014, 9 million new TB cases were reported worldwide; of these, 1.5 million cases died and 0.4 million cases were HIV-positive. ${ }^{2}$ 
Another factor that contributes to this high mortality is the conventional therapies used for TB treatment. The lengthy treatment period (several months) and the use of several drugs (for reviews of treatment, see Jadhavar et al) ${ }^{3}$ result in various side effects, including neurotoxicity and hepatotoxicity as the most common adverse effects. Therefore, patients cease treatment before the recommended period required for eradication of TB, which can result in the development of multidrugresistant TB (MDR-TB) and extensively drug-resistant TB. ${ }^{4}$

Therefore, the searches for new therapeutic agents that result in shorter treatment time, lower toxicity, efficacy against resistant strains, and less interaction with antiretroviral therapies has intensified in recent decades. ${ }^{5}$ Currently, various organic compounds, such as BTZ043, PA-824, SQ109, and sutezolid, are in phases II and III clinical trials. In addition, Sirturo ${ }^{\circledR}$ (bedaquiline; Janssen Pharmaceutica, Beerse, Belgium) and Deltyba ${ }^{\circledR}$ (delamanid; Otsuka Novel Products $\mathrm{GmbH}$, München, Germany) have been approved by the US Food and Drug Administration (FDA) and the European Medicines Agency (EMA), respectively, as add-on therapies for the treatment of MDR-TB. ${ }^{6}$

Although some agents have been approved, new anti-TB drugs are still scarce and M. tuberculosis may exhibit resistance to antibiotics. ${ }^{7}$ However, medicinal inorganic chemistry research encompassing metal complexes has made great advances in recent decades. ${ }^{8}$

Metal-based complexes have displayed promising activity against several diseases such as TB, arthritis, and cancer. ${ }^{9}$ Thus, they are considered possible alternatives for TB treatment owing to their differing coordination numbers and geometries, which explain their different mechanisms of action compared to conventional organic drugs. ${ }^{10}$

Copper has a number of qualities that have made it attractive for such research. Used since ancient times, it operates as a first-row transition metal, is the third most abundant trace metal in the human body (behind iron and zinc), is important for plants, animals and fundamental to the performance of several enzymes involved in energy metabolism, respiration, and deoxyribonucleic acid (DNA) synthesis. ${ }^{11}$

Copper(II) complexes, formed from the interaction of copper(II) ions with biologically active ligands, have shown excellent antimicrobial activity against $M$. tuberculosis. ${ }^{12}$ Salsbury et a ${ }^{13}$ showed that copper(II) complexes containing lipophilic hydroxypyridinone-derived ligands ( $2 \mathrm{a}$ and $2 \mathrm{~h}$ ) exhibited considerable antimicrobial activity against $M$. tuberculosis $\mathrm{H}_{37} \mathrm{R}_{\mathrm{a}}$ with a minimum inhibitory concentration (MIC) of $12.50 \mu \mathrm{g} / \mathrm{mL}$ for both complexes. In addition, Hoffman et $\mathrm{al}^{14}$ demonstrated that copper(II) pyrophosphate complexes
$\left[\mathrm{Cu}\right.$ (phen) $\left.\left(\mathrm{H}_{2} \mathrm{O}\right)\left(\mathrm{H}_{2} \mathrm{P}_{2} \mathrm{O}_{7}\right)\right]$ (phen =1,10'-phenanthroline) showed promising antimicrobial activity against $\mathrm{M}$. tuberculosis $\mathrm{H}_{37} \mathrm{R}_{\mathrm{v}}$ with an MIC of $31.25 \mu \mathrm{g} / \mathrm{mL}$.

However, the low solubility of metallic compounds in water makes their application in several in vivo experiments unfeasible. ${ }^{15}$ To minimize this problem, nanostructured systems have been developed in order to increase the solubility of the active substance and create a controlled-release system, which maintains the drug plasma concentration within the therapeutic range for several hours or days, and results in decreased toxicity and increased patient compliance. ${ }^{16}$

To solve these problems, our research group has recently developed nanostructured lipid systems such as microemulsions with the aim of improving the solubility of the copper(II) complexes. Evaluation of the antimicrobial activity showed the activity and selectivity of the copper(II) complexes against bacteria, such as Staphylococcus aureus and Escherichia coli, were increased after the incorporation of the complexes into these systems, by analysis of cellular viability ${ }^{15}$ Another study conducted by the same group showed that the copper(II) complexes loaded into nanostructured lipid systems also exhibited increased activity against M. tuberculosis. ${ }^{17}$ Therefore, research into nanostructured systems has intensified in order to improve the solubility of copper(II) complexes and achieve controlled release. ${ }^{18}$

Nanostructured lipid carriers (NLCs), known as secondgeneration solid lipid nanoparticles (SLNs), are prepared using a mixture of liquid and solid lipids at room temperature that form an imperfect lipid matrix. SLNs and NLCs can easily be scaled up and present a low cost, which allows them to meet the needs of the pharmaceutical and cosmetic industries, thus ensuring a promising commercial future. ${ }^{19}$ However, NLCs have many advantages over SLNs: a wider concentration of surfactants and co-surfactants can be used, their matrices can incorporate a greater amount of lipophilic drugs, expulsion during storage is minimized, controlled and sustained release is favored, toxicity, degradation, and adverse reactions are reduced, as well as improved physical and chemical stability. ${ }^{20,21}$

Because of the advantages of this system, excellent results have been reported over the past decades for many applications, such as oral, topical, parenteral pulmonary, and ocular administration; NLCs have displayed better performance in the production of pharmaceutical forms including tablets, pellets, capsules, creams, and injectables. ${ }^{22,23}$

Therefore, the incorporation of copper(II) complexes into NLCs aimed at oral administration may minimize the treatment duration of TB, which would enable more effective treatment and greater patient compliance. ${ }^{8}$ 
In the present study, NLCs were developed and characterized, employing polyoxyethylene 40 stearate (E-40) (2.07\%), caprylic/capric triglyceride (CCTG) $(2.05 \%)$, and polyoxyl 40 hydrogenated castor oil (PEG-40) (0.88\%) $(0.88 \%)$ as the lipid phase, and poloxamer 407 (P-407) (3.50\%) and/or cetyltrimethylammonium bromide (CTAB) $(0.50 \%)$ as the aqueous phase. This system was used as a tool to evaluate the potential of NLCs for incorporation of three copper(II) complexes that contain INH as a ligand: $\left[\mathrm{CuCl}_{2}(\mathrm{INH})_{2}\right] \cdot \mathrm{H}_{2} \mathrm{O}(1),\left[\mathrm{Cu}(\mathrm{NCS})_{2}(\mathrm{INH})_{2}\right] \cdot 5 \mathrm{H}_{2} \mathrm{O}(2)$, and $\left[\mathrm{Cu}(\mathrm{NCO})_{2}(\mathrm{INH})_{2}\right] \cdot 4 \mathrm{H}_{2} \mathrm{O}(3)$. We evaluated the in vitro activity of copper(II) complexes 1, 2, and 3-loaded NLCs using a resazurin microtiter assay (REMA) as well as their in vivo acute toxicity, in order to determine the potential for improved activity against $M$. tuberculosis.

\section{Materials and methods Materials}

E-40 (Sigma-Aldrich Co., St Louis, MO, USA), CCTG (Via Farma, São Paulo, SP, Brazil), PEG-40 (Pharma Special, Itapevi, São Paulo, Brazil), P-407 (Pluronic ${ }^{\circledR}$ F127, Sigma-Aldrich Co.), and CTAB (Sigma-Aldrich Co.) were used to develop the NLCs. Middlebrook $7 \mathrm{H} 9$ broth supplemented with oleic acid, albumin, dextrose, and catalase (OADC) (Becton-Dickinson, Franklin Lakes, NJ, USA), resazurin, and rifampicin (Sigma-Aldrich Co.) were used to investigate the in vitro biological activity. Ultrapure water (EMD Millipore Billerica, MA, USA) was used in this study.

\section{Methods}

\section{Synthesis of copper(II) complexes}

$\mathrm{CuCl}_{2} \cdot 2 \mathrm{H}_{2} \mathrm{O}$, isoniazid ( $\left.\mathrm{INH}\right)$, sodium thiocyanate ( $\mathrm{NaSCN}$ ), and potassium cyanate $(\mathrm{KCNO})$ were purchased from Sigma-Aldrich Co. Methanol was purchased from EMD Millipore Billerica. All the solutions were prepared using deionized water from a Millipore filtration system (EMD Millipore Billerica). The copper(II) complexes $\left[\mathrm{CuCl}_{2}(\mathrm{INH})_{2}\right] \cdot \mathrm{H}_{2} \mathrm{O}(1),\left[\mathrm{Cu}(\mathrm{NCS})_{2}(\mathrm{INH})_{2}\right] \cdot 5 \mathrm{H}_{2} \mathrm{O}(2)$, and $\left[\mathrm{Cu}(\mathrm{NCO})_{2}(\mathrm{INH})_{2}\right] \cdot 4 \mathrm{H}_{2} \mathrm{O}(3)$ were synthesized according to Silva et al. ${ }^{15}$

\section{Development of NLCs}

All dispersions of NLCs were prepared by the melt emulsification method of Souto et al. ${ }^{21}$ The molten lipid phase (E-40, CCTG, and PEG-40) was poured onto a composite or non-aqueous phase consisting of a mixture of surfactants (P-407 and/or CTAB) and ultrapure water (Milli-Q), which was heated to approximately $5^{\circ} \mathrm{C}-10^{\circ} \mathrm{C}$ above its melting point $\left(70^{\circ} \mathrm{C}\right)$. The mixture was then stirred for $30 \mathrm{~s}$ using a magnetic stirrer, which yielded a pre-emulsion. The final formulations were prepared using an ultrasonic processor (Q700 Sonicator, Qsonica, Newtown, CT, USA) operated for $20 \mathrm{~min}$ at intervals of $30 \mathrm{~s}$ (amplitude, 8\%; power rating, $700 \mathrm{~W}$; probe diameter, 1/16), and maintained in an ice bath throughout the procedure. The formulations were centrifuged (Spectrafuge $^{\mathrm{TM}}$, 16M Microcentrifuge, Labnet International, Inc., Edison, NJ, USA) at 5,000 rpm for $10 \mathrm{~min}$ to remove titanium eliminated during the sonication process. The formulations were then packaged in amber bottles and stored in a refrigerator $\left(4^{\circ} \mathrm{C} \pm 2^{\circ} \mathrm{C}\right)$.

The incorporation of the copper(II) complexes 1, 2, and 3 into the NLCs was carried out during the pre-emulsion phase at a concentration of $5,000 \mu \mathrm{g} / \mathrm{mL}^{17}$

Determination of the mean hydrodynamic diameter and polydispersity index (PDI)

The mean hydrodynamic diameter (Z-Ave or d.nm) and PDI were determined by dynamic light scattering (DLS, Zetasizer Nano NS, Malvern Instruments, Malvern, UK). Each dispersion of NLCs was diluted in ultrapure water at a ratio of 1:100. All experiments were conducted in triplicate at $25^{\circ} \mathrm{C}$, and the results were expressed as mean \pm standard deviation (mean $\pm \mathrm{SD})$.

\section{Zeta potential (ZP) analysis}

The ZP of the NLCs was assessed by the electrophoretic mobility of the particles according to the HelmholtzSmoluchowski equation, and processed using the Zetasizer Nano equipment software NS (Malvern Instruments). Each dispersion of NLCs was diluted in ultrapure water at a ratio of 1:100. The $\mathrm{ZP}$ analysis was performed in triplicate at $25^{\circ} \mathrm{C}$, and the results were expressed as mean \pm SD.

\section{Physical stability}

The physical stability of the F11 NLCs and those loaded with the copper(II) complexes 1, 2, and 3 was assessed via determination of Z-Ave (d.nm) and ZP after 1, 15, 30, 45, and 60 days, as shown in Figures 1 and 2, respectively. The data were evaluated using analysis of variance (ANOVA) followed by Tukey's post hoc test (Statistica 7 software). A difference was considered significant at a $P$-value $<0.05$.

\section{Atomic force microscopy (AFM)}

The morphology of the NLCs was determined by AFM (Dimension Icon, Bruker) using the intermittent contact mode. 


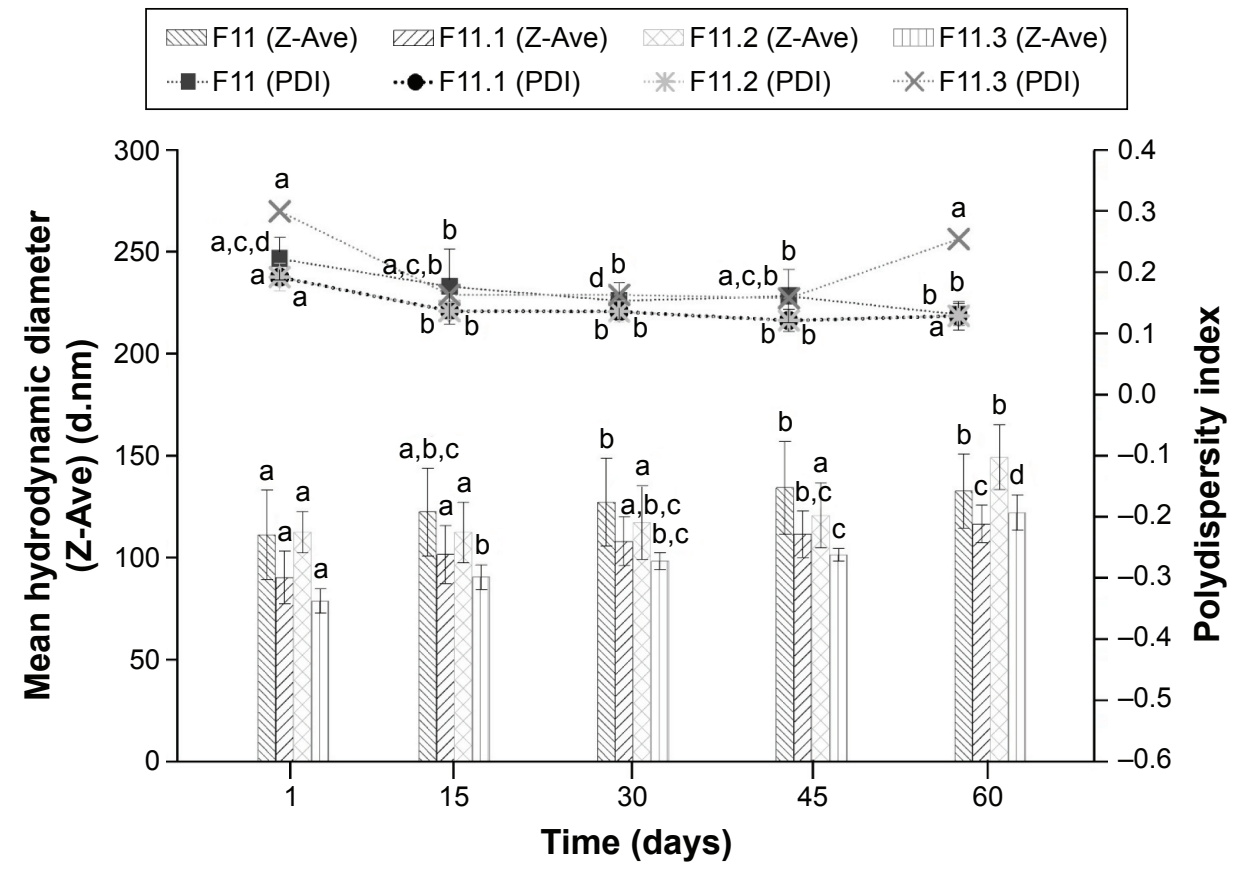

Figure I Determination of the mean hydrodynamic diameter (Z-Ave) (d.nm) and polydispersity index versus time in days (mean \pm standard deviation; $\mathrm{n}=3$ ). Note: ${ }^{a-d}$ Different letters in each column indicate that the differences between means were statistically significant $(P<0.05)$.

A drop of each NLC dispersion was added on the mica and centrifuged using a spin coater (Spin Coater Centrifuge - SPI Supplies, Model KW-4A) at $500 \mathrm{rpm}$ for $30 \mathrm{~s}$, followed by $5,000 \mathrm{rpm}$ for $1 \mathrm{~min}$. The sample surface was scanned using a silicon probe (cantilever/tip), which covered an area of $5 \times 5 \mu \mathrm{m}$ at a frequency of $1 \mathrm{~Hz}$.

\section{Differential scanning calorimetry (DSC)}

Thermal events were investigated by DSC, using a TA Instruments Model DSC Q100 analyzer. The samples (approximately $5 \mathrm{mg}$ ) were placed in $40 \mu \mathrm{L}$ aluminum cans. Afterward, each sample was heated from $-50^{\circ} \mathrm{C}$ to $350^{\circ} \mathrm{C}$ at a rate of $10^{\circ} \mathrm{C} / \mathrm{min}$. High-purity nitrogen was used

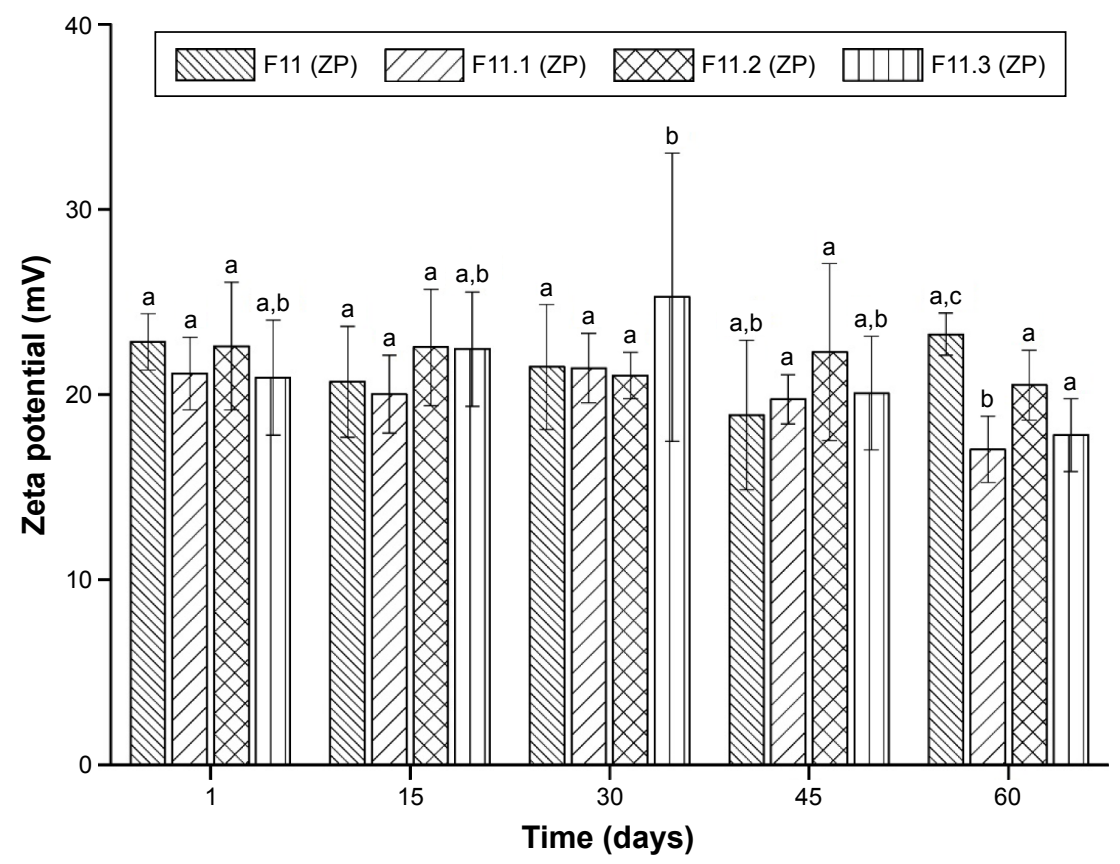

Figure 2 Values of zeta potential $(\mathrm{mV})$ versus time in days (mean \pm standard deviation; $n=3$ ).

Note: ${ }^{a-c}$ Different letters in each column indicate a statistically significant difference between means $(P<0.05)$.

Abbreviation: ZP, zeta potential. 
as the purging gas, which was supplied at a flow rate of $50 \mathrm{~mL} / \mathrm{min}$.

\section{Determination of the MIC}

The MIC was determined by a REMA according to Palomino et al. ${ }^{24}$ Stock solutions of the tested complexes were prepared in dimethyl sulfoxide (DMSO) or in the NLCs at a concentration of 5,000 $\mu \mathrm{g} / \mathrm{mL}$ and diluted with Middlebrook 7H9 broth supplemented with OADC prepared by Precision XS (Biotek ${ }^{\circledR}$, Winooski, VT, USA), to obtain a final drug concentration range of $0.09-25 \mu \mathrm{g} / \mathrm{mL}$. Rifampicin was dissolved in DMSO and used as the standard drug. A suspension of M. tuberculosis $\mathrm{H}_{37} \mathrm{R}_{\mathrm{v}}$ ATCC 27294 was cultured in Middlebrook $7 \mathrm{H} 9$ broth supplemented with OADC and $0.05 \%$ Tween 80 . When the culture reached the turbidity of McFarland standard No 1, corresponding to $5 \times 10^{5} \mathrm{CFU} / \mathrm{mL}$, $100 \mu \mathrm{L}$ of the inoculum was added to each well of a $96-$ well microplate in addition to $100 \mu \mathrm{L}$ of the tested complexes. Each experiment was conducted in triplicate. The plates were incubated for 7 days at $37^{\circ} \mathrm{C}$. Resazurin $(30 \mu \mathrm{L}, 0.01 \%$ in water) was added. After $24 \mathrm{~h}$, the fluorescence of the wells was measured using a Cytation 3 (Biotek). The MIC was defined as the lowest concentration resulting in $90 \%$ inhibition of the growth of M. tuberculosis.

\section{Acute toxicity study in Swiss mice}

The in vivo acute toxicity assay (median lethal dose, $\mathrm{LD}_{50}$ ) was performed according to the Organization for Economic Cooperation Development (OECD) with some modifications. The $\mathrm{LD}_{50}$ value for a substance is the dose required to kill half a tested population after a specified test duration. ${ }^{25}$ Female Swiss mice (4-8 weeks old, 20-40 g) were purchased from Botucatu Central Biotério. The experimental protocol was performed in accordance with the Guide for the Care and Use of Laboratory Animals and the Ethical Principles for Animal Experimentation established by the Brazilian Committee for Animal Experimentation (COBEA). This investigation was approved by the animal experimentation ethics committee of the School of Pharmaceutical Science/UNESP (Protocol CEUA/FCF/Car $\mathrm{N}^{\circ}$ 78/2015), and complied with international laws. Swiss mice were maintained in polycarbonate cages at $23^{\circ} \mathrm{C} \pm 2{ }^{\circ} \mathrm{C}$ and $(56 \pm 2) \%$ humidity under a 12 hour light/ dark cycle and specific pathogen-free conditions. They were provided with food and water ad libitum. ${ }^{26}$ The control groups received sunflower oil (SO) and F11 NLC. The complexes were administered at a concentration of $1,000 \mathrm{mg} / \mathrm{kg}$ bodyweight via gavage as a single oral dose ( $\mathrm{n}=6$ animals/group). When a complex resulted in accidental loss of more than $50 \%$ of the animals, doses of 300 and $500 \mathrm{mg} / \mathrm{kg}$ bodyweight were administered. Over 14 days, the animals were examined by evaluation of behavioral parameters such as Hippocratic screening. Then, the mice were euthanized in $\mathrm{CO}_{2}$ chambers. Data were analyzed using ANOVA followed by Dunnett's test (GraphPad Prism 6.0 software). Values of $P<0.05$ were considered statistically significant.

\section{Quantification of the enzymatic activity of aspartate} aminotransferase (AST) and alanine aminotransferase (ALT) in the serum of Swiss mice

After the acute toxicity study, in order to investigate whether any biochemical changes occurred in the liver, AST and ALT enzymatic activities were determined in the serum of mice 14 days after administration of the complexes. Blood samples $(500 \mu \mathrm{L})$ were collected from the submandibular vein. ${ }^{27}$ Blood samples were placed in tubes, centrifuged at $3,500 \mathrm{rpm}$ for $15 \mathrm{~min}$ to separate the serum, stored at $-70^{\circ} \mathrm{C}$, and analyzed on the day of collection.

The enzymes were analyzed using biochemical assay kits for AST and ALT. Data were analyzed using ANOVA followed by Dunnett's test (GraphPad Prism 6.0 software). Values of $P<0.05$ were considered statistically significant.

\section{Results and discussion}

The methodology of Das et $\mathrm{al}^{28}$ was adapted for the development of NLCs by sonication. We developed twelve formulations, F1, F2, F3, F4, F5, and F6 containing 2.07\% E-40, $2.05 \%$ CCTG, and $0.88 \%$ PEG-40 as the lipid phase and $\mathrm{P}-407$ as the aqueous phase at the following concentrations: $1,2,2.5,3,3.5$, and 4\%, respectively. The formulations, F7, F8, F9, F10, F11, and F12 were composed of the same lipid phase with various P-407 concentrations: 1, 2, 2.5, 3, 3.5 , and $4 \%$, respectively, with $0.5 \%$ CTAB added to the aqueous phase. Table 1 lists the different NLCs with their respective components.

The twelve NLCs developed were visually observed and characterized via determination of the mean hydrodynamic diameter (Z-Ave, d.nm) and PDI between 1 and 30 days of storage (Table 2). The formulation selected for subsequent physicochemical characterization (Figures 1 and 2) was F11, because the cationic charge of the CTAB in the formulation likely promoted the interaction of the NLCs with the negatively charged wall of $M$. tuberculosis. In addition, the analysis of Z-Ave and PDI of the formulations was an essential part of this selection, as shown in Table 2.

The copper(II) complexes $\left[\mathrm{CuCl}_{2}(\mathrm{INH})_{2}\right] \cdot \mathrm{H}_{2} \mathrm{O}(1)$, $\left[\mathrm{Cu}(\mathrm{NCS})_{2}(\mathrm{INH})_{2}\right] \cdot 5 \mathrm{H}_{2} \mathrm{O}(2)$, and $\left[\mathrm{Cu}(\mathrm{NCO})_{2}(\mathrm{INH})_{2}\right] \cdot 4 \mathrm{H}_{2} \mathrm{O}(3)$ were loaded into the NLCs during the pre-emulsion phase 
Table I NLC components

\begin{tabular}{lllllll}
\hline NLCs & E-40 & \multicolumn{2}{l}{ Composition (\%) } & CTAB & $\begin{array}{l}\text { Water } \\
\text { (Milli-Q) }\end{array}$ \\
\cline { 3 - 5 } & & CCTG & PEG-40 & P-407 & & 94.00 \\
FI & 2.07 & 2.05 & 0.88 & 1.00 & - & 93.00 \\
F2 & 2.07 & 2.05 & 0.88 & 2.00 & - & 92.50 \\
F3 & 2.07 & 2.05 & 0.88 & 2.50 & - & 92.00 \\
F4 & 2.07 & 2.05 & 0.88 & 3.00 & - & 91.50 \\
F5 & 2.07 & 2.05 & 0.88 & 3.50 & - & 91.00 \\
F6 & 2.07 & 2.05 & 0.88 & 4.00 & - & 93.50 \\
F7 & 2.07 & 2.05 & 0.88 & 1.00 & 0.50 & 92.50 \\
F8 & 2.07 & 2.05 & 0.88 & 2.00 & 0.50 & 92.00 \\
F9 & 2.07 & 2.05 & 0.88 & 2.50 & 0.50 & 92.00 \\
FI0 & 2.07 & 2.05 & 0.88 & 3.00 & 0.50 & 91.50 \\
FII & 2.07 & 2.05 & 0.88 & 3.50 & 0.50 & 91.00 \\
FI2 & 2.07 & 2.05 & 0.88 & 4.00 & 0.50 & 90.50 \\
\hline
\end{tabular}

Note: Column I contains the respective carrier formulations with the respective compositions studied.

Abbreviations: NLC, nanostructured lipid carrier; CCTG, caprylic/capric triglyceride; PEG-40, polyoxyl 40 hydrogenated castor oil; P-407, poloxamer 407; CTAB, cetyltrimethylammonium bromide.

at a concentration of $5,000 \mu \mathrm{g} / \mathrm{mL}$ to prepare F11.1, F11.2, and F11.3, respectively (Figures 1 and 2).

The different NLCs, developed with or without CTAB surfactant, were analyzed via determination of Z-Ave (d.nm) and PDI as shown in Table 2.

For NLCs to be kinetically stable, the mean diameter must be on a nanometer scale $(10-1,000 \mathrm{~nm}) .{ }^{29} \mathrm{~F} 1, \mathrm{~F} 2, \mathrm{~F} 3, \mathrm{~F} 4, \mathrm{~F} 5$, and $\mathrm{F} 6$ exhibited mean diameter values from $87.54 \pm 0.89$ to $118.80 \pm 1.86 \mathrm{~nm}$ over 30 days, whereas the NLCs containing CTAB showed lower mean diameter values between $49.50 \pm 0.19$ and $93.75 \pm 0.56 \mathrm{~nm}$ over the same time (Table 2).

Our results corroborate those of Hejri et a ${ }^{30}$ and Souto et $\mathrm{al},{ }^{21}$ which showed that the use of a combination of surfactants in NLC preparation minimizes the surface tension

Table 2 Values expressed as mean \pm SD of the mean hydrodynamic diameter and PDI of the NLCs developed $(n=3)$

\begin{tabular}{|c|c|c|c|c|}
\hline & \multicolumn{2}{|c|}{ Mean Z-Ave (d.nm) \pm SD } & \multicolumn{2}{|c|}{ Mean PDI \pm SD } \\
\hline & I day & 30 days & I day & 30 days \\
\hline $\mathrm{FI}$ & $90.06 \pm 0.99$ & $106.10 \pm 0.77$ & $0.28 \pm 0.02$ & $0.18 \pm 0.01$ \\
\hline F2 & $102.20 \pm 1.47$ & $112.40 \pm 1.05$ & $0.35 \pm 0.05$ & $0.19 \pm 0.01$ \\
\hline F3 & $87.54 \pm 0.89$ & $108.10 \pm 1.25$ & $0.30 \pm 0.02$ & $0.18 \pm 0.01$ \\
\hline $\mathrm{F} 4$ & $103.50 \pm 1.06$ & $118.80 \pm 1.86$ & $0.26 \pm 0.01$ & $0.15 \pm 0.01$ \\
\hline F5 & $88.24 \pm 0.13$ & $108.80 \pm 1.62$ & $0.27 \pm 0.01$ & $0.14 \pm 0.0 \mid$ \\
\hline F6 & $96.83 \pm 0.77$ & || $1.70 \pm 1.31$ & $0.28 \pm 0.01$ & $0 .|4 \pm 0.0|$ \\
\hline F7 & $49.50 \pm 0.19$ & $75.94 \pm 1.41$ & $0.19 \pm 0.01$ & $0.32 \pm 0.01$ \\
\hline F8 & $77.24 \pm 1.76$ & $70.08 \pm 0.29$ & $0.4 I \pm 0.0 I$ & $0.22 \pm 0.01$ \\
\hline F9 & $83.76 \pm 1.52$ & $83.88 \pm 0.08$ & $0.42 \pm 0.02$ & $0.28 \pm 0.01$ \\
\hline FIO & $70.59 \pm 0.33$ & $82.47 \pm 1.16$ & $0.32 \pm 0.03$ & $0.24 \pm 0.01$ \\
\hline $\mathrm{FII}$ & $83.36 \pm 0.24$ & $93.75 \pm 0.56$ & $0.26 \pm 0.01$ & $0.25 \pm 0.01$ \\
\hline $\mathrm{FI} 2$ & $83.57 \pm 5.63$ & $92.38 \pm 1.44$ & $0.23 \pm 0.01$ & $0.22 \pm 0.01$ \\
\hline
\end{tabular}

Abbreviations: NLCs, nanostructured lipid carriers; SD, standard deviation; $\mathrm{PDI}$, polydispersity index. of the system, and results in a smaller diameter than that of NLCs containing only one aqueous phase surfactant.

The PDI determines the particle size distribution: PDI values of approximately 0.2 indicate monodispersed particles, ${ }^{31}$ whereas PDI values $>0.4$ indicate a polydisperse distribution or high SD. ${ }^{32}$

F1, F2, F3, F4, F5, and F6 exhibited PDI values ranging from $0.14 \pm 0.01$ to $0.35 \pm 0.05$ over 30 days, and F7, F8, F9, F10, F11, and F12 showed PDI values from $0.19 \pm 0.01$ to $0.42 \pm 0.02$ (Table 2) over the same time, which indicated the monodispersity of the NLCs.

According to the Z-Ave and PDI of the formulations prepared with CTAB, F11 was selected as it exhibited mean diameter values with low $\mathrm{SD}$, and $\mathrm{PDI}$ values with an increase of less than 0.25 over 30 days.

Figure 1 shows the physical stability of the NLC, F11, and the copper(II) complexes 1, 2, and 3-loaded F11 NLC, which was used to determine the Z-Ave and PDI over 60 days.

The differences between the mean hydrodynamic diameter and PDI of the different NLCs, before and after incorporation of copper(II) complexes, were statistically significant.

The particle diameters of F11, F11.1, F11.2, and F11.3 ranged from $111.27 \pm 21.86$ to $134.25 \pm 22.72 \mathrm{~nm}, 90.27 \pm 12.97$ to $116.46 \pm 9.17 \mathrm{~nm}, 112.4 \pm 10.22$ to $149.3 \pm 15.82 \mathrm{~nm}$, and $78.65 \pm 6.00$ to $122.00 \pm 8.70 \mathrm{~nm}$, respectively (Figure 1). F11 significantly showed the same particle diameter as F11.2 in the 60 days, however, when compared with F11.1 and F11.3 showed the larger particle diameter. These results can be explained by difficulties in the measurement technique. The measurement of particle size is not directly affected, but the intensity of fluctuation of the light scattering is altered by the movement of the particles. ${ }^{33}$ All NLCs showed PDI values ranging from $0.13 \pm 0.01$ to $0.30 \pm 0.09$ (Figure 1), which were consistent with those described by Ali et al. ${ }^{34}$ Despite the statistically significant differences, both the particle diameter and PDI were still within the acceptable values for lipid nanoparticles (Z-Ave $<300 \mathrm{~nm}$ and PDI $<0.4$ ), which indicated that the NLCs obtained showed homogeneous particle size distribution that prevented the formation of agglomerates.

Our results supported the hypothesis that the use of surfactants ensured system stability. According to Severino et $a l,{ }^{35}$ the use of more than one surfactant in the formulation may result in the formation of an arrangement of spherical micelles on the surface of the NLCs: a film is produced at the interface, which ensured more efficient surface coverage and prevented the agglomeration of the NLCs. 
Figure 2 describes the physical stability in terms of ZP $(\mathrm{mV})$ of the NLC, F11, and of the copper(II) complexes 1, 2, and 3-loaded F11 over 60 days.

$\mathrm{ZP}$ is a crucial factor to ensure the physical stability of the colloidal dispersions such as NLCs. A ZP value of approximately $\pm 30 \mathrm{mV}$ is considered desirable because this results in stable NLCs without particle aggregation due to repulsive forces ${ }^{36}$ Briefly, ZP values of approximately $\pm 20 \mathrm{mV}$ ensure the stability of the NLC dispersions over time. ${ }^{28}$

The ZP of the NLCs varied significantly over the 60 day storage period, except for F11.2. ZP values ranged from $18.87 \pm 4.04$ to $23.25 \pm 1.13 \mathrm{mV}, 17.03 \pm 1.77$ to $21.42 \pm 1.87 \mathrm{mV}$, $20.51 \pm 1.88$ to $22.60 \pm 3.44 \mathrm{mV}$, and $17.80 \pm 1.96$ to $25.25 \pm 7.78 \mathrm{mV}$ for F11, F11.1, F11.2, and F11.3, respectively (Figure 2).

These results are in accordance with the data obtained regarding the mean diameter and PDI; they suggested that positively charged particles were formed for all NLCs. This supports the hypothesis that the addition of the cationic surfactant $\mathrm{CTAB}$ caused greater electrostatic repulsion between the particles, which increased the physical stability of the formulations during storage, since the cationic surface of the NLCs probably aids the entrapment of water-insoluble drugs by the reduction, or prevention, of their expulsion during the storage period. ${ }^{37,38}$

The morphology of the NLCs was analyzed by AFM, as shown in Figure 3. The images of formulations A, B, C, and $\mathrm{D}$ show particles with spherical morphology (Figure 3). In the photomicrograph, $\mathrm{A}$ and $\mathrm{D}$, the particle diameters were approximately $50-80 \mathrm{~nm}$ and $78-93 \mathrm{~nm}$, respectively, which were lower than the values measured by DLS. The photomicrographs $\mathrm{B}$ and $\mathrm{C}$ showed particle diameters of approximately $140-180 \mathrm{~nm}$ and $156-159 \mathrm{~nm}$, respectively, which were greater than the values detected by DLS; this corroborated the results described by zur Muhlen et al, ${ }^{39}$ who found that the diameter measured by an AFM-based technique was approximately $210-225 \mathrm{~nm}$, whereas the diameter measured by DLS was approximately $160 \mathrm{~nm}$. However, the use of these techniques allowed the evaluation
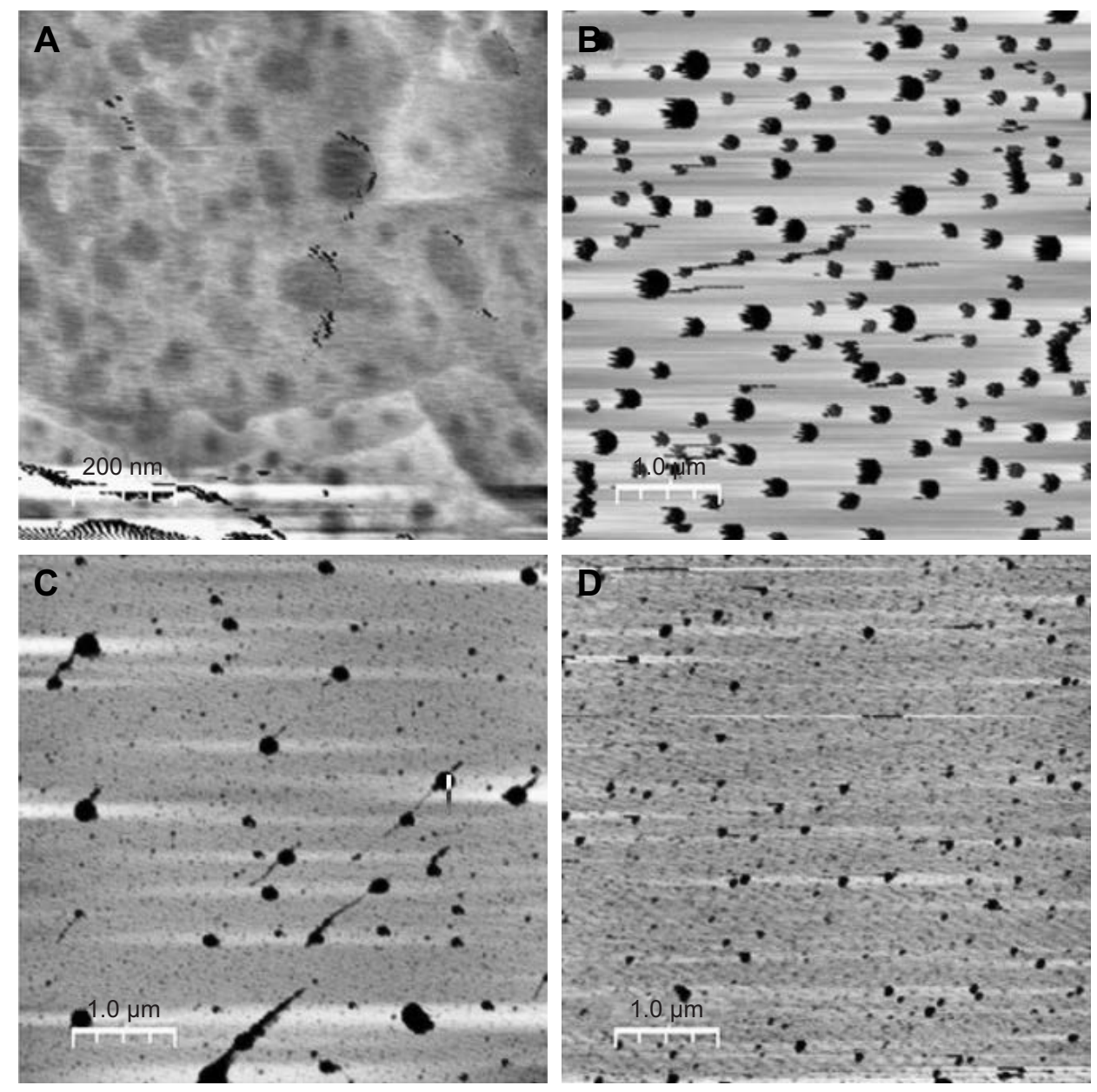

Figure 3 Two-dimensional images of photomicrographs of NLCs: (A) FII, (B) FII.I, (C) FII.2, and (D) FII.3. Abbreviation: NLCs, nanostructured lipid carriers. 
of the particle size, and indicated that all were distributed at the nanoscale.

DSC allows the qualitative and quantitative analysis of the physical and chemical properties of materials through heating or cooling, variations in enthalpy, endothermic and exothermic processes, melting, and vaporization. ${ }^{40}$

Figure 4 shows DSC scans of free copper(II) complexes 1,2 , and 3 and the individual components used in the preparation of the NLCs.

The free copper(II) complexes did not have a melting peak (Figure 4). According to Cides et al, ${ }^{41}$ the absence of melting point in DSC scans may indicate the component has remained in its amorphous form. INH-linked copper(II) complexes had a melting temperature of $170^{\circ} \mathrm{C}-173^{\circ} \mathrm{C},{ }^{42}$ however, it was not observed in the scans, which suggested that INH was inserted into the copper(II) complexes.

Table 3 shows the melting points of the individual components used in the NLC preparations.

The DSC scans of E-40 showed a melting point of $52.45^{\circ} \mathrm{C}$, which was not consistent with the values found in literature $\left(38^{\circ} \mathrm{C}\right) .^{43}$ This melting point may occur through the possible rearrangement of the crystalline structure, which may result in more stable or less stable polymorphic forms that alter the melting temperature. ${ }^{44}$

The DSC scan showed an endothermic event in CCTG, related to a melting process at $-5^{\circ} \mathrm{C}$. The DSC scan of PEG-40

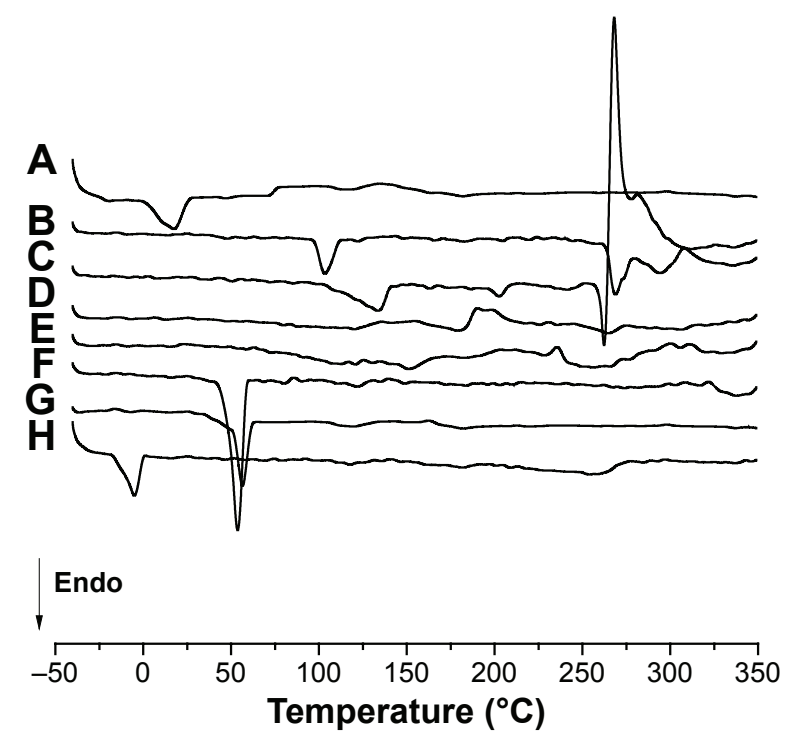

Figure 4 DSC scans of free copper(II) complexes I, 2, and 3 and the components used in preparation of NLCs: (A) polyoxyl-40 hydrogenated castor oil (PEG-40); (B) cetyltrimethylammonium bromide (CTAB); (C) $\left[\mathrm{CuCl}_{2}(\mathrm{INH})_{2}\right] \cdot \mathrm{H}_{2} \mathrm{O}$ (I); (D) $\left[\mathrm{Cu}(\mathrm{NCS})_{2}(\mathrm{INH})_{2}\right] \cdot 5 \mathrm{H}_{2} \mathrm{O}(2) ;(\mathrm{E})\left[\mathrm{Cu}(\mathrm{NCO})_{2}(\mathrm{INH})_{2}\right] \cdot 4 \mathrm{H}_{2} \mathrm{O}(3)$; (F) poloxamer 407 (P-407); (G) polyoxyethylene 40 stearate (E-40); (H) caprylic/capric triglyceride (CCTG).

Abbreviations: CTAB, cetyltrimethylammonium bromide; DSC, differential scanning calorimetry; NLCs, nanostructured lipid carriers; Endo, endhotermic.
Table 3 Melting points of the NLC components: E-40, CCTG, PEG-40, P-407, and CTAB

\begin{tabular}{ll}
\hline Components & MP $\left({ }^{\circ} \mathbf{C}\right)$ \\
\hline E-40 & 52.45 \\
CCTG & -5.67 \\
PEG-40 & 16.87 \\
P-407 & 55.67 \\
CTAB & 103.93 \\
\hline
\end{tabular}

Abbreviations: NLC, nanostructured lipid carrier; E-40, polyoxyethylene 40 stearate; CCTG, caprylic/capric triglyceride; PEG-40, polyoxyl 40 hydrogenated castor oil; P-407, poloxamer 407; CTAB, cetyltrimethylammonium bromide; MP, melting point.

showed an endothermic event at its melting point $\left(16^{\circ} \mathrm{C}\right)$, which confirmed the data provided by the manufacturer (BASF; Ludwigshafen, Rhineland-Palatinate, Germany).

The DSC scan of P-407 showed a well-defined endothermic event at $55^{\circ} \mathrm{C}$, a value close to that described by Rigon et a ${ }^{45}$ $\left(59^{\circ} \mathrm{C}\right)$. The DSC scan of CTAB showed three well-defined melting peaks, the first at $103.93^{\circ} \mathrm{C}$, the second at $270^{\circ} \mathrm{C}$, and the third at $295^{\circ} \mathrm{C}$. According to Bottom, ${ }^{46}$ the presence of more than one melting point may indicate polymorphism.

Figure 5 shows the DSC scans of the F11 NLC and copper(II) complex-loaded NLCs. For all formulations, endothermic events indicate the melting point. It was observed that the DSC scans of the NLCs included the peaks corresponding to the individual components, such as CCTG at approximately $-5.67^{\circ} \mathrm{C}$ (the line in Figure 5 indicates this melting point), $\mathrm{PEG}-40$ at approximately $-15^{\circ} \mathrm{C}, \mathrm{CTAB}$ at approximately $98^{\circ} \mathrm{C}$ and $118^{\circ} \mathrm{C}$, similar peaks can be identified in the copper complexes. Also, at approximately $50^{\circ} \mathrm{C}$, there were peaks in P-407 $\left(55.67^{\circ} \mathrm{C}\right)$ and $\mathrm{E}-40\left(52.45^{\circ} \mathrm{C}\right)$.

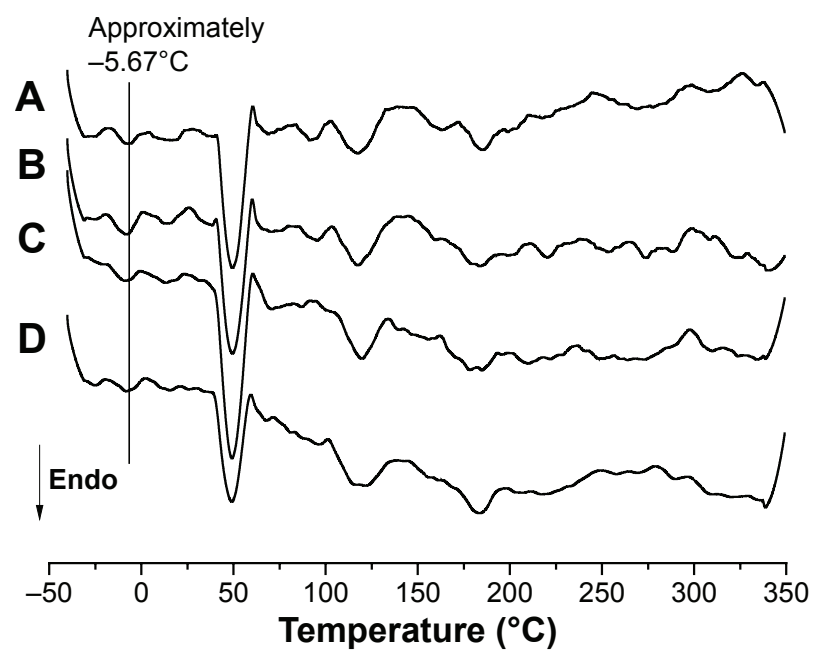

Figure 5 DSC scans of the FI I NLC and copper(II) complex-loaded NLCs, (A) FI I, (B) FII.I, (C) FII.2, and (D) FII.3.

Abbreviations: DSC, differential scanning calorimetry; NLCs, nanostructured lipid carriers; Endo, endhotermic. 
The MIC of copper(II) complexes 1, 2, and 3 solubilized in DMSO and those loaded into the F11 NLC, against M. tuberculosis $\mathrm{H}_{37} \mathrm{R}_{v}$, was determined using a REMA as shown in Table 4.

Free complexes 1, 2, and 3 showed weak in vitro antimicrobial activity: the MIC values of complexes 1, 2, and 3 were $103.63 \mu \mathrm{g} / \mathrm{mL}, 63.26 \mu \mathrm{g} / \mathrm{mL}$, and $80.71 \mu \mathrm{g} / \mathrm{mL}$, respectively (Table 4). These results indicated weaker antimicrobial activity than those described by Hunoor et $\mathrm{al}^{47}$ in which copper(II) complex with hydrazone Schiff base ligands $\left[\mathrm{Cu}(\mathrm{ACINH}) \mathrm{Cl} \cdot \mathrm{H}_{2} \mathrm{O}\right] \cdot 3 \mathrm{H}_{2} \mathrm{O}(\mathrm{ACINH}=3-$ acetylcoumarin-isonicotinoylhydrazone) showed an MIC value of $50 \mu \mathrm{g} / \mathrm{mL}$.

In the loaded complexes, 1, 2, and 3 MIC values were dramatically decreased from 103.63 to $1.87 \mu \mathrm{g} / \mathrm{mL}, 63.26$ to $2.31 \mu \mathrm{g} / \mathrm{mL}$, and 80.71 to $1.96 \mu \mathrm{g} / \mathrm{mL}$, respectively. Thus, the antimicrobial activity of the complexes was enhanced by 55.4, 27.3, and 41.1 times, respectively, when incorporated into the NLCs.

This study is the first to investigate the antimicrobial activity of copper(II) complexes loaded into NLCs against M. tuberculosis; however, the results obtained in this study were compared to those of other studies that depicted the in vitro antimycobacterial activity of copper(II) complexes against $M$. tuberculosis.

Our results of the copper(II) complexes loaded into the NLCs showed better tuberculostatic activity against M. tuberculosis $\mathrm{H}_{37} \mathrm{R}_{\mathrm{v}}$ than the values reported by Mandewale et al, ${ }^{48}$ wherein the copper(II) complexes bound to hydrazone ligands showed MIC values ranging from $6.25-12.5 \mu \mathrm{g} / \mathrm{mL}$ and the free ligands displayed MIC values from $25-50 \mu \mathrm{g} / \mathrm{mL}$.

After the incorporation of copper(II) complexes into NLCs, the MIC values were considerably better than some conventional TB therapies. ${ }^{49}$ For example, the MIC value in

Table 4 In vitro antimicrobial activities of the free copper(II) complexes and those loaded into the NLCs expressed as the MIC values $(\mu \mathrm{g} / \mathrm{mL}$ and $\mu \mathrm{mol} / \mathrm{L})$

\begin{tabular}{lll}
\hline Complexes & MIC $(\mu \mathrm{g} / \mathrm{mL})$ & MIC $(\mu \mathrm{mol} / \mathrm{L})$ \\
\hline $\mathrm{I}$ & $103.63 \pm 37.07$ & $253.0 \pm 90.70$ \\
2 & $63.26 \pm 36.52$ & $1 \mathrm{I} 6.0 \pm 67.12$ \\
3 & $80.7 \mathrm{I} \pm 38.47$ & $163.0 \pm 77.89$ \\
$\mathrm{FII}$ & $2.47 \pm \mathrm{I} .0 \mathrm{I}$ & $2.47 \pm 1.0 \mathrm{I}$ \\
$\mathrm{FIII}$ & $\mathrm{I} .87 \pm 0.12$ & $4.57 \pm 0.29$ \\
FII .2 & $2.3 \mathrm{I} \pm \mathrm{I} .42$ & $4.24 \pm 2.6 \mathrm{I}$ \\
FII.3 & $\mathrm{I} .96 \pm \mathrm{I} .32$ & $3.97 \pm 2.67$ \\
Rifampicin & $0.400 \pm 0.0 \mathrm{I}$ & $0.522 \pm 0.0 \mathrm{I}$ \\
\hline
\end{tabular}

Abbreviations: NLCs, nanostructured lipid carriers; MIC, minimum inhibitory concentration.
$\mathrm{H}_{37} \mathrm{R}_{\mathrm{v}}$ for pyrazinamide ranged from 6.0 to $50.0 \mu \mathrm{g} / \mathrm{mL}$; for rifampicin, used as the control treatment in this test, the $\mathrm{MIC}_{90}$ value was $0.400 \mu \mathrm{g} / \mathrm{mL}$, and these values demonstrated that the MIC value obtained with the complexes loaded into the NLCs are sufficient to use these compounds in TB therapy. ${ }^{50}$ Based on these results, the NLCs were able to increase the tuberculostatic activity, which might be attributed to the cationic surface of the NLCs that favored the interaction of the system with the negatively charged cell wall of $M$. tuberculosis. This mutual interaction increased the antimicrobial activity of copper(II) complexes against mycobacteria. ${ }^{51,52}$

Silva et a $1^{15,17}$ performed cytotoxicity assays $\left(\mathrm{IC}_{50}\right)$ of complexes 1, 2, and 3 using Vero (ATCC ${ }^{\circledR}$ CCL-81), J774A.1 (ATCC ${ }^{\circledR}$ TIB-67), and MRC-5 (ATCC ${ }^{\circledR}$ CCL-171) cell lines. No toxic effects of the complexes were identified. In addition to cell viability, the toxicity of the complexes in an alternative model, Artemia salina L. (Artemide), was verified and evaluated; the metal complexes were also determined to be non-toxic.

With regard to the safety of the components used in the formulations (E-40, CCTG, PEG-40, P-407, and CTAB), there are numerous studies reporting their use in the pharmaceutical, cosmetic, and food industries. Generally, no irritation or toxicity was observed in acute toxicity studies in animals (dogs, rats, and rabbits). ${ }^{43}$

Given the previous results of our group, the safety profile of copper(II) complex-loaded NLCs was evaluated by the classical acute toxicity study $\left(\mathrm{LD}_{50}\right)$ in Swiss mice according to the OECD method, with some modifications. ${ }^{53}$ Figure 6 shows the percentage survival of animals examined over 14 days after a single administration of free copper(II) complexes 1, 2, and 3 and of those administered copper(II) loaded into the the F11 NLC and SO, via gavage at a dose of $1,000 \mathrm{mg} / \mathrm{kg}$ bodyweight.

Figure 6 shows $100 \%$ survival for the control (SO), control (F11), 2, F11.2, and F11.3. Moreover, Figures 7 and 8 show the $100 \%$ survival of animals after a single administration of free complex 1 via gavage at doses of $500 \mathrm{mg} / \mathrm{kg}$ and $300 \mathrm{mg} / \mathrm{kg}$ bodyweight, respectively.

The control groups, SO and F11, showed 100\% survival. The $\mathrm{LD}_{50}$ of free complex 1 could not be determined in the group receiving doses of $1,000 \mathrm{mg} / \mathrm{kg}$ (Figure 6), $500 \mathrm{mg} / \mathrm{kg}$ (Figure 7), and $300 \mathrm{mg} / \mathrm{kg}$ bodyweight (Figure 8 ) due to the loss of $100 \%$ of mice by $24 \mathrm{~h}$ after administration of the dose, which indicated the toxicity of the complex. The groups that received free complexes 2 and 3 at a dose of $1,000 \mathrm{mg} / \mathrm{kg}$ showed $100 \%$ and $83.3 \%$ survival, respectively. From these results, we can infer that the $\mathrm{LD}_{50}$ is greater than $1,000 \mathrm{mg} / \mathrm{kg}$ and thus does not need to be determined. 


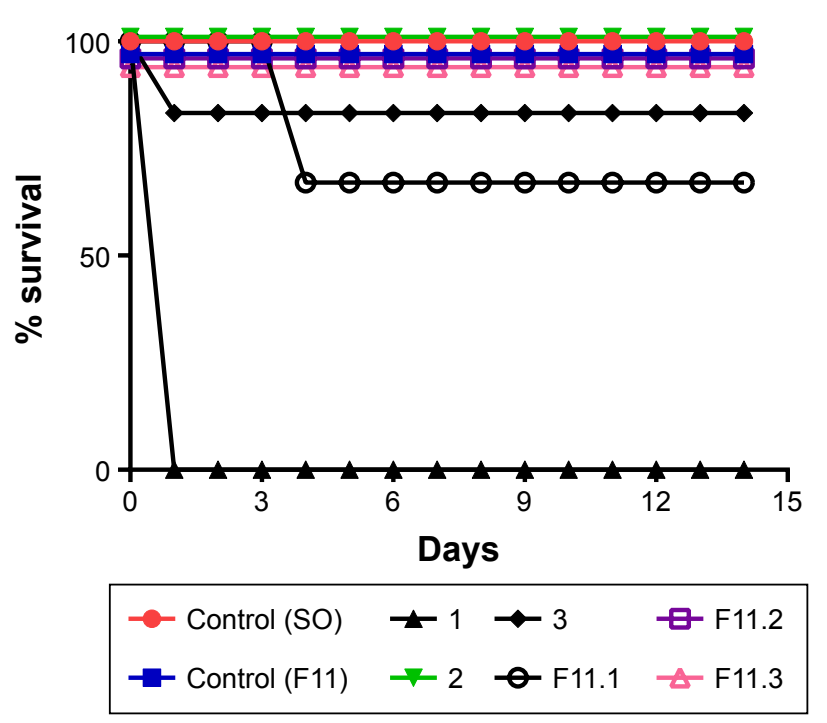

Figure 6 Percentage survival of Swiss mice over 14 days after a single administration of free copper(II) complexes I, 2, and 3 and of those administered copper(II) loaded into the FII NLC and SO, via gavage at a dose of I,000 mg/kg bodyweight. Abbreviations: NLC, nanostructured lipid carrier; SO, sunflower oil.

When complex 1 was incorporated into F11 NLC and administered to Swiss mice via gavage at a dose of $1,000 \mathrm{mg} / \mathrm{kg}$ bodyweight, only two animals were lost after 4 days of administration; a $67 \%$ survival rate. By the comparison of this value to the group administered complex 1 solubilized in SO, it was inferred that the NLC reduced the toxicity of complex 1 ; therefore, the maximum dosage $(1,000 \mathrm{mg} / \mathrm{kg})$ did not allow us to calculate the $\mathrm{LD}_{50}$, as the survival rate was greater than $50 \%$ in this group.

The groups that received copper(II) complexes 2 and 3 loaded into the NLC F11 (F11.2 and F11.3) at a dose of $1,000 \mathrm{mg} / \mathrm{kg}$ bodyweight showed $100 \%$ survival.

These results suggested that incorporation of copper(II) complexes in NLCs reduced their toxicity, as none of the

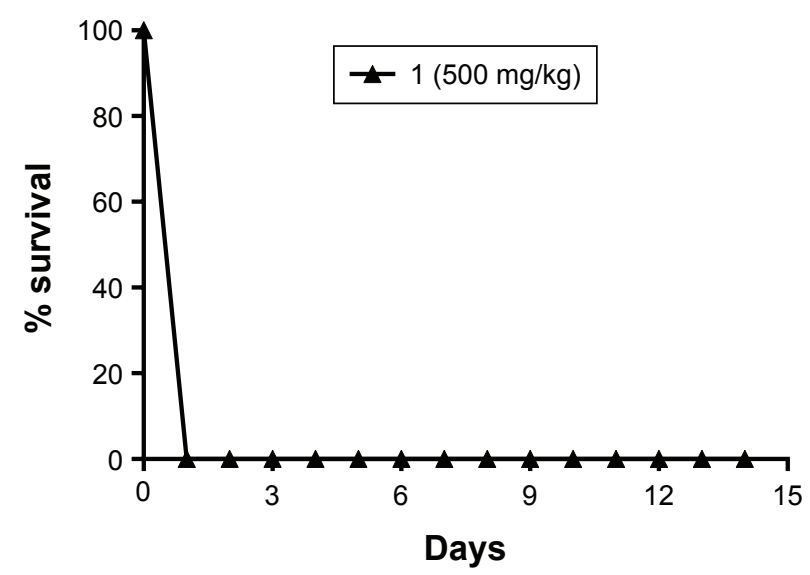

Figure 7 Percentage survival of Swiss mice over 14 days after a single administration of free copper(II) complex I via gavage at a dose of $500 \mathrm{mg} / \mathrm{kg}$ bodyweight.

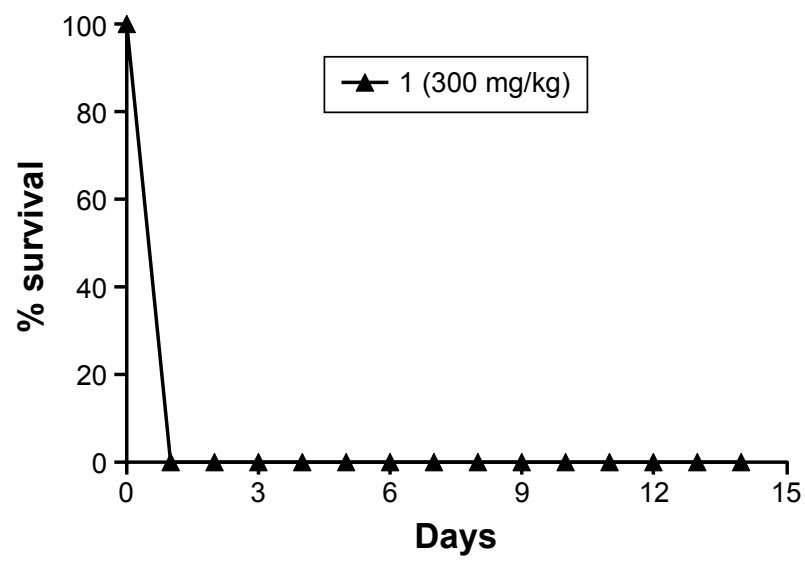

Figure 8 Percentage survival of Swiss mice over I 4 days after a single administration of free copper(II) complex I via gavage at a dose of $300 \mathrm{mg} / \mathrm{kg}$ bodyweight.

groups receiving complexes (1-3) loaded into NLC F11 showed $50 \%$ loss of animals. Therefore, it was not possible to calculate the $\mathrm{LD}_{50}$ at a dose of $1,000 \mathrm{mg} / \mathrm{kg}$ bodyweight.

With regard to the behavioral parameters (Hippocratic screening), in which the animals were monitored and assessed over 14 days of treatment starting from the second day, only the animals that received F11.2 and F11.3 at a dose of $1,000 \mathrm{mg} / \mathrm{kg}$ bodyweight showed behavioral changes, such as piloerection and defecation (dark feces); however, there was no mortality.

Quantification of the hepatic enzymes, including AST and ALT, is widely performed since these are among the most important liver transaminases. These hepatic markers can detect heart and liver damage. ${ }^{54,55}$ Liver cell damage results in the release of these enzymes into the bloodstream; thus, serum AST and ALT levels increase. However, ALT acts as a specific hepatic marker that only detects liver damage, whereas AST is considered a nonspecific marker, which can be released from the liver, erythrocytes, and skeletal and cardiac muscles. ${ }^{56,57}$ Figure 9 shows the changes in serum AST and ALT activity levels.

No statistically significant differences were observed between the control groups (OS and F11) and the groups treated with complexes 2 and 3 or F11.1, F11.2, and F11.3. Our results are in accordance with those of Lopes et al. ${ }^{25}$

Although the serum AST and ALT levels were slightly elevated or close to that of the control groups (OS and F11), the values were within acceptable limits. Based on the results of ANOVA and Dunnett's test, the differences were not statistically significant $(P>0.05)$. These results suggest that Swiss mice treated with complexes 2 and 3 or F11.1, F11.2, and F11.3 over 14 days did not suffer liver toxicity or cardiovascular disease. Thus, the formulations did not present significant potential hepatotoxicity or cardiotoxicity. 


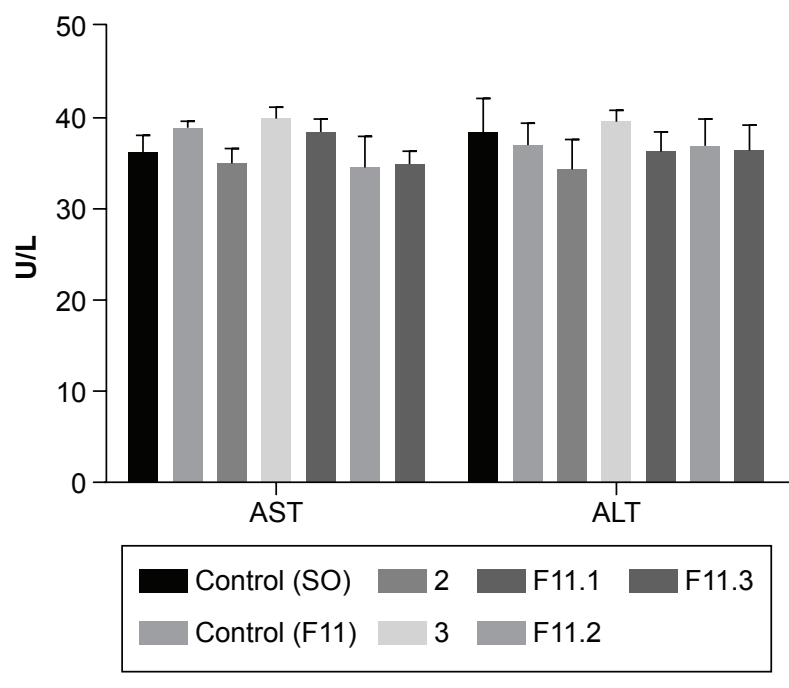

Figure 9 Quantification of the serum aspartate aminotransferase (AST) and alanine aminotransferase (ALT) activity levels in Swiss mice in terms of units per liter (U/L). The differences between the means were not statistically significant $(P>0.05)$. Abbreviations: ALT, alanine aminotransferase; AST, aspartate aminotransferase; SO, sunflower oil; U/L, units per liter.

\section{Conclusion}

Our results showed that copper(II) complex-loaded NLCs showed significantly lower variation in the particle diameter, PDI and ZP, which resulted in good physical stability of NLCs over 60 days owing to the nanoscale size of the spherical particles in the dispersions. In vitro biological activity showed that copper(II) complex-loaded NLCs enhanced the antimicrobial activity against $M$. tuberculosis by up to 27 times. Moreover, they did not exert toxicity in Vero (ATCC CCL-81), J774A.1 (ATCC TIB-67), and MRC-5 (ATCC CCL-171) cell lines. An acute toxicity study in Swiss mice showed that the incorporation of copper(II) complexes into NLCs reduced their toxicity; this was confirmed via quantification of the enzymatic activity of AST and ALT, which showed no significant changes. Thus, NLCs may be promising tools for the incorporation of copper(II) complexes for potential applications against mycobacteria.

\section{Acknowledgments}

We thank Dr Maria Palmira Daflon Gremião and Dr Leila Chiavacchi of the Department of Drugs and Medicines, School of Pharmaceutical Sciences of Araraquara UNESP for their partnership and the use of materials and equipment. AFM facilities were provided by Dr Marcelo AP da Silva of Instituto de Física de São Carlos - USP. This work was financially supported by Coordenação de Aperfeiçoamento de Pessoal de Nível Superior (CAPES), (grant \#2013/09265-7 and grant \#2016/12038-0) São Paulo Research Foundation (FAPESP), Conselho Nacional de Desenvolvimento Científico e Tecnológico (CNPq), and
Programa de Apoio ao Desenvolvimento Científico da Faculdade de Ciências Farmacêuticas (PADC-FCF-UNESP).

\section{Disclosure}

The authors report no conflicts of interest in this work.

\section{References}

1. Nogueira AF, Facchinetti V, Souza MV, Vasconcelos TR. Tuberculose: uma abordagem geral dos principais aspectos. [Tuberculosis: a general approach of the main aspects] Rev Bras Farm. 2012;93(1):3-9. Portuguese.

2. World Health Organization. Global Tuberculosis Report 2015. Geneva: World Health Organization Press; 2015. Available from: http://apps. who.int/iris/bitstream/10665/191102/1/9789241565059_eng.pdf. Accessed February 3, 2017.

3. Jadhavar PS, Vaja MD, Dhameliya TM, Chakraborti AK. Oxazolidinones as anti-tubercular agents: discovery, development and future perspectives. Curr Med Chem. 2015;22(38):4379-4397.

4. Drobniewski F, Nikolayevsky V, Maxeiner H, et al. Rapid diagnostics of tuberculosis and drug resistance in the industrialized world: clinical and public health benefits and barriers to implementation. BMC Med. 2013;11:190.

5. Sharma AK, Kumar R, Nishal B, Das O. Nanocarriers as promising drug vehicles for the management of tuberculosis. BioNanoSci. 2013; 3(2):102-111.

6. Bonnet M, Bastard M, Cros P, et al. Identification of patients who could benefit from bedaquiline or delamanid: a multisite MDR-TB cohort study. Int J Tuberc Lung Dis. 2015;20(2):177-186.

7. Olaru ID, von Groote-Bidlingmaier F, Heyckendorf J, Yew WW, Lange C, Chang KC. Novel drugs against tuberculosis: a clinician's perspective. Eur Respir J. 2015;45(4):1119-1131.

8. Sato MR, Silva PB, Souza RA, Santos KC, Chorilli M. Recent advances in nanoparticle carriers for coordination complexes. Curr Top Med Chem. 2015;15(4):287-297.

9. Medici S, Peana M, Nurchi VM, Lachowicz JI, Crisponi G, Zoroddu MA. Noble metals in medicine: latest advances. Coord Chem Rev. 2015;284:329-350.

10. Pavan FR, Poelhsitz GV, Barbosa MI, et al. Ruthenium(II) phosphine/ diimine/picolinate complexes: inorganic compounds as agents against tuberculosis. Eur J Med Chem. 2011;46(10):5099-5107.

11. Rodrigues MA, Silva PP, Guerra W. Cobre. [Copper]. QNEsc. 2012;34: 161-162.

12. Speer A, Shrestha TB, Bossmann SH, et al. Copper-boosting compounds: a novel concept for antimycobacterial drug discovery. Antimicrob Agents Chemother. 2013;57(2):1089-1091.

13. Salsbury LE, Robertson KN, Flewelling AJ, et al. Anti-mycobacterial activities of copper(II) complexes. Part II. Lipophilic hydroxypyridinones derived from maltol. Can J Chem. 2015;93(3):334-340.

14. Hoffman AE, DeStefano M, Shoen C, et al. Co(II) and $\mathrm{Cu}$ (II) pyrophosphate complexes have selectivity and potency against Mycobacteria including Mycobacterium tuberculosis. Eur J Med Chem. 2013; 70:589-593.

15. Silva PB, Bonifácio BV, Frem RC, et al. A nanostructured lipid system as a strategy to improve the in vitro antibacterial activity of copper(II) complexes. Molecules. 2015;20(12):22534-22545.

16. de Freitas ES, Silva PB, Chorilli M, et al. Nanostructured lipid systems as a strategy to improve the in vitro cytotoxicity of ruthenium(II) compounds. Molecules. 2014;19(5):5999-6008.

17. Silva PB, Souza PC, Calixto GM, et al. In vitro activity of copper(II) complexes, loaded or unloaded into a nanostructured lipid system, against Mycobacterium tuberculosis. Int J Mol Sci. 2016;17(5):745.

18. Bonifácio BV, Ramos MA, da Silva PB, et al. Nanostructured lipid system as a strategy to improve the anti-Candida albicans activity of Astronium sp. Int J Nanomedicine. 2015;10:5081-5092. 
19. Radtke M, Muller RH. Nanostructured lipid drug carriers. New Drugs. 2001;48-52.

20. Yang Y, Corrona A 3rd, Schubert B, Reeder R, Henson MA. The effect of oil type on the aggregation stability of nanostructured lipid carrier. J Colloid Interface Sci. 2014;418:261-272.

21. Souto EB, Severino P, Santana MHA, Pinho SC. Nanopartículas de lipídicos sólidos: métodos clássicos de produção laboratorial. [Solid lipid nanoparticles: classical methods of lab production]. Quím Nova. 2011;34(10):1762-1769. Portuguese.

22. Muller RH, Radtke M, Wissing AS. Solid lipid nanoparticles (SLN) and nanostructured lipid carriers (NLC) in cosmetic and dermatological preparations. Adv Drug Deliv Rev. 2002;54(Suppl 1):S131-S155.

23. Muller RH, Radtke M, Wissing AS. Nanostructured lipid matrices for improved microencapsulation of drugs. Int J Pharm. 2002;242(1-2): 121-128.

24. Palomino JC, Martin A, Camacho M, Guerra H, Swings J, Portaels F. Resazurin microtiter assay plate: simple and inexpensive method for detection of drug resistance in Mycobacterium tuberculosis. Antimicrob Agents Chemother. 2002;46(8):2720-2722.

25. Lopes Ede O, Oliveira CG, Silva PB, et al. Novel zinc(II) complexes [ $\mathrm{Zn}($ atc-Et)2] and [ $\mathrm{Zn}($ atc- $\mathrm{Ph}) 2]$ : in vitro and in vivo antiproliferative studies. Int J Mol Sci. 2016;17(5):E781.

26. Gruppo V, Johnson CM, Marietta KS, et al. Rapid microbiologic and pharmacologic evaluation of experimental compounds against Mycobacterium tuberculosis. Antimicrob Agents Chemother. 2006; 50(4):1245-1250.

27. Golde WT, Gollobin P, Rodriguez LL. A rapid, simple, and humane method for submandibular bleeding of mice using a lancet. Lab Anim (NY). 2005;34(9):39-43.

28. Das S, Ng WK, Tan RB. Are nanostructured lipid carriers (NLCs) better than solid lipid nanoparticles (SLNs): development, characterizations and comparative evaluations of clotrimazole-loaded SLNs and NLCs? Eur J Pharm Sci. 2012;47(1):139-151.

29. Fonseca-Santos B, Gremião MP, Chorilli M. Nanotechnology-based drug delivery systems for the treatment of Alzheimer's disease. Int $J$ Nanomedicine. 2015;10:4981-5003.

30. Hejri A, Khosravi A, Gharanjig K, Hejazi M. Optimisation of the formulation of $\beta$-carotene loaded nanostructured lipid carriers prepared by solvent diffusion method. Food Chem. 2013;141(1):117-123.

31. Schwarz C, Mehnert W, Lucks J, Müller R. Solid lipid nanoparticles (SLN) for controlled drug delivery. I. Production, characterization and sterilization. J Control Release. 1994;30(1):83-96.

32. Krause B, Mende M, Potschke P, Petzold G. Dispersability and particle size distribution of CNTs in an aqueous surfactant dispersion as a function of ultrasonic treatment time. Carbon. 2010;48:2746-2754.

33. Iqbal MA, Md S, Sahni JK, Baboota S, Dang S, Ali J. Nanostructured lipid carriers system: recent advances in drug delivery. J Drug Target. 2012;20(10):813-830

34. Ali H, El-Sayed K, Sylvester PW, Nazzal S. Molecular interaction and localization of tocotrienol-rich fraction (TRF) within the matrices of lipid nanoparticles: evidence studies by differential scanning calorimetry (DSC) and proton nuclear magnetic resonance spectroscopy ((1) H NMR). Colloids Surf B Biointerfaces. 2010;77(2):286-297.

35. Severino P, Pinho SC, Souto EB, Santana MH. Polymorphism, crystallinity and hydrophilic-lipophilic balance of stearic acid and stearic acid-capric/caprylic triglyceride matrices for production of stable nanoparticles. Colloids Surf B Biointerfaces. 2011;86(1):125-130.

36. Tan SW, Billa N, Roberts CR, Burley JC. Surfactant effects on the physical characteristics of amphotericin B-containing nanostructured lipid carriers. Colloids Surf A Physicochem Eng Asp. 2010; 372(1-3):73-79.

37. Obeidat WM, Schwabe K, Muller RH, Kech CM. Preservation of nanostructured lipid carriers (NLC). Eur J Pharm Biopharm. 2010; 76(1):56-67.

38. Saupe A, Gordon KC, Rades T. Structural investigations on nanoemulsions, solid lipid nanoparticles and nanostructured lipid carriers by cryofield emission scanning electron microscopy and Raman spectroscopy. Int J Pharm. 2006;314(1):56-62.
39. zur Muhlen A, zur Muhlen E, Niehus H, Mehnert W. Atomic force microscopy studies of solid lipid nanoparticles. Pharm Res. 1996;13(9): $1411-1416$

40. Lira A, Araújo A, Basílio I, Santos B, Santana D, Macedo R. Compatibility studies of lapachol with pharmaceutical excipients for the development of topical formulations. Thermochim Acta. 2007;457(1-2):1-6.

41. Cides LC, Araújo AA, Santos-Filho M, Matos J. Thermal behaviour, compatibility study and decomposition kinetics of glimepiride under isothermal and non-isothermal conditions. J Therm Anal Calorim. 2006; 84(2):441-445.

42. Lavor EP, Freire FD, Aragão FS, Raffin FN, Moura TF. Application of thermal analysis to the study of anti-tuberculosis drug compatibility. Part 1. J Therm Anal Calorim. 2012;108(1):207-212.

43. Rowe RC, Sheskey PJ, Owen SC. Handbook of Pharmaceutical Excipients. 5th ed. London: Pharmaceutical Press; 2006.

44. Silva RC, Escobedo JP, Gioielli LA. Comportamento de cristalização de lipídios estruturados por interesterificação química de banha e óleo de soja. [Crystalization behavior of structured lipids by chemical interesterification of lard and soybean oil]. Quím Nova. 2008;31(2):330-335. Portuguese.

45. Rigon RB, Fachinetti N, Severino P, Santana MHA, Chorilli M. Skin delivery and in vitro biological evaluation of trans-resveratrol-loaded solid lipid nanoparticles for skin disorder therapies. Molecules. 2016;21(1):E116.

46. Bottom R. The role of modulated temperature differential scanning calorimetry in the characterization of molecule exhibiting polymorphic and glass forming tendencies. Int J Pharm. 1999;92(1):47-53.

47. Hunoor RS, Patil BR, Badiger DS, et al. Spectroscopic, magnetic and thermal studies of $\mathrm{Co}(\mathrm{II}), \mathrm{Ni}(\mathrm{II}), \mathrm{Cu}(\mathrm{II})$ and $\mathrm{Zn}$ (II) complexes of 3-acetylcoumarin-isonicotinoylhydrazone and their antimicrobial and anti-tubercular activity evaluation. Spectrochim Acta A Mol Biomol Spectrosc. 2010;77(4):838-844.

48. Mandewale MC, Thorat B, Shelke D, Yamgar R. Synthesis and biological evaluation of new hydrazone derivatives of quinoline and their $\mathrm{Cu}$ (II) and $\mathrm{Zn}$ (II) complexes against Mycobacterium tuberculosis. Bioinorg Chem Appl. 2015;2015:153015.

49. dos Santos ER, Mondeli MA, Pozzi LV, et al. New ruthenium(II)/ phosphines/diimines complexes: promising antitumor (human breast cancer) and Mycobacterium tuberculosis fighting agents. Polyhedron. 2013;51:292-297.

50. Global Alliance for TB drug development. Handbook of anti-tuberculosis agents. Tuberculosis. 2008;88(2):85-170.

51. Ayla-Torre C, Hernández N, Galeano A, Novoa-Aponte L, Soto C. Zeta potential as a measure of the surface charge of mycobacterial cells. Ann Microbiol. 2014;64(3):1189-1195.

52. Stokes RW, Norris-Jones R, Brooks DE, Beveridge TJ, Doxsee D, Thorson LM. The Glycan-rich outer layer of the cell wall of Mycobacterium tuberculosis acts as an antiphagocytic capsule limiting the association of the bacterium with macrophages. Infect Immun. 2004;72(10):5676-5686.

53. OECD.org [homepage on the Internet]. Guideline 423: Acute Oral Toxicity-Acute Toxic Class Method. Paris: Head of Publications Service; 2011. Available from: http://www.oecd.org/publications. Accessed March 23, 2016.

54. Liu X, Hamnvik PO, Chamberland JP, et al. Circulating alanine transaminase (ALT) and $\gamma$-glutamyltransferase (GGT), but not fetuin-A, is associated with metabolic risk factors, at baseline and at two-year follow-up: the prospective Cyprus metabolism study. Metabolism. 2014;63(6):773-782.

55. Sohn W, Jun DW, Kwak MJ, et al. Upper limit of normal serum alanine and aspartate aminotransferase levels in Korea. J Gastroenterol Hepatol. 2013;28(3):522-529.

56. Amir N, Suprayitno E, Nursyam HH. The effect of cypermethrin on Jambal Roti to AST and ALT levels the Wistar rat (Rattusnorvegicus). Int J Pharm Tech Res. 2015;8(2):235-240.

57. Hyder MA, Hasan M, Mohieldein AH. Comparative levels of ALT, AST, ALP and GGT in liver associated diseases. Eur J Exp Biol. 2013; 3(2):280-284. 


\section{Publish your work in this journal}

Drug Design, Development and Therapy is an international, peerreviewed open-access journal that spans the spectrum of drug design and development through to clinical applications. Clinical outcomes, patient safety, and programs for the development and effective, safe, and sustained use of medicines are the features of the journal, which has also been accepted for indexing on PubMed Central. The manuscript management system is completely online and includes a very quick and fair peer-review system, which is all easy to use. Visit http://www.dovepress.com/testimonials.php to read real quotes from published authors.

Submit your manuscript here: http://www.dovepress.com/drug-design-development-and-therapy-journal 